\title{
Perspectives of parents with children using hearing aids
}

\begin{abstract}
Objective: To verify the perspectives of the parents with children using hearing aids.

Methods: The questionnaires were delivered to the parents in ENT/Audiology consultations in the Hospital Espírito Santo E.P.E. - Angra do Heroísmo and Hearing Aid DispensaryGAES. The study population consisted of twenty parents between 23 and 60years old with children aged between 0 and 10years, users of conventional hearing aids.
\end{abstract}

Results: Parents react similarly manner when they receive the diagnosis. However they have different views towards the children and the use of hearing aids.

Conclusion: This work revealed that some of the parents didn't reach the full acceptance of the child's condition.

Keywords: children, hearing loss, hearing aids, parents, parental behavior, stages of elizabeth kubler-ross
Volume 3 Issue 3 - 2015

\section{Ana Vieira}

Department of Audiologist, School of Allied Health Sciences Polytechnic Institute of Porto (ESTSP-IPP), Portugal

Correspondence: Ana Vieira, Department of Audiologist, Rua das Covas n.3 São Brás, 9760-655 Praia da Vitória, Azores, Portugal,Tel+35I 926332789, Email anavieira-21@hotmail.com

Received: February 08, 2015 | Published: September 23, 2015

\section{Introduction}

The ear is the organ that provides one of the highest functions of the human being that is communication. It's through language that the child can understand the world around her, transmit and abstract thoughts and feelings of the other, interact in the environment and acquire knowledge. The development of a hearing child obviously will not occur in the same way that a child with hearing loss. There are serious barriers that the child with hearing loss will have to overcome, particularly in the absence of communication, broader educational and social difficulties. ${ }^{1}$ Thus the early detection of hearing loss is extremely important, for the prevention or reduction of possible risks that may arise in the overall development of the child (Oliveira et al., 1998). ${ }^{1}$

It's noteworthy that $90 \%$ of children with hearing loss have hearing parents. ${ }^{2}$ For parents of a child with hearing loss, the world is different from the time it's diagnosed. Different phases are experienced by parents so they can understand, adapt and accept the difference on the child, although these phases don't occur sequentially or not all parents experience them the same way. ${ }^{3}$ According to Elizabeth Kubler-Ross there are five stages which in this case the parents suffer after the hearing loss diagnosis of the child, namely: Negation, Anger; Bargaining, Depression and Acceptance. ${ }^{4}$

\section{Materials and methods}

Participants: This study consisted of 20 parents with children users of hearing aids. Participant's age ranged between 23 and 60years old, with higher prevalence between 30 and 39years. Regarding marital status of the parents ranged from married, single, divorced and widow. The parent's professions are diverse, ranging from less skilled professions to professions with higher educational.

The children were between the ages of 0 to 10years old. As for gender, twelve children were male and six female. Regarding the etiology of the hearing loss, mostly are unknown, however there are some cases of prematurity, Rubella, Meningitis and HIV. A big part of the children has a severe degree of hearing loss. The hearing aid adaptation is essentially bilateral; only five children were adapted unilaterally. The time between the diagnosis and rehabilitation ranged from two to eight months.

\section{Procedures}

The sample was obtained through a questionnaire delivered on the Hospital do Espírito Santo de Angra do Heroísmo and Hearing Aid Dispensary-GAES. The questionnaire was validated by different professional areas, including Phonetics, Psychology, Audiology and Statistics.

\section{Discussion and results}

The main objective of this study was to verify if the parents reached the acceptance stage, according to the stages of Elizabeth Kubler-Ross. To verify this they must have several positive responses when placing issues on children and the use of hearing aids. On the first question ("What did you feel when you were told about your child's diagnosis?"). Throught the questionnaires, it was possible to verify that the first reaction, for all parents, was shock. This reaction is confirmed in the literature by Luterman, which describes that immediately after receiving the diagnosis; the reaction of parents of children with hearing loss is shock. ${ }^{5}$ On question 2 ("Nowadays, how do you feel about the child's hearing loss?"), after the initial shock, parents recognize the calamity of diagnosis and have different reactions. Nine of the parents said acceptance; six mentioned revolt and rejection of the situation; and only one parent reported failure. According to the theory of Elizabeth Kubler-Ross, parents who reported rejection, are in denial stage. This is a temporary defense mechanism and its intensity and duration depends on how the parents suffer. It's also common at this stage the parent doesn't believe at the diagnosis.

Parents were asked about the daily use of the hearing aids on the child. According to the answers, we found out that some of the parents reported that the child uses hearing aids only sometimes, when they have a greater need to use it. This reflects difficulty for the parents to understand the real need of the use of hearing aids. Several authors report that it's difficult for the family to admit socially the child's hearing loss and this occurs at the time she is starting to use 
the hearing aid. It displays a deficit that was invisible until then. The fitting of the hearing aids is one of the fundamental conditions for the child with hearing loss develop their full potential, which will occur only when she uses hearing aids a greater number of hours per day. ${ }^{3}$

In question 8 ("As a parent is it easy to communicate/understand the child?") half of the sample under study, reported that only sometimes it's easy to communicate/understand the child. And two parents said it's not easy to communicate/understand the child. Lederberg and Prezbindowski argue that the difficulty of communication is what most disturbs the child's development. Therefore, some behavioral problems such as aggressive behavior, disobedience, parents describe how frustrating both are for them and for the children being based on communication barriers. ${ }^{2}$

On the question 10 ("What do you do when someone comments about the hearing aid?"), taking into account the proposed options, we found out that some parents feel uncomfortable and choose not to answer. With this information the parents reveal that they have some difficulty in talking about it and expose the child deficit. According to a study of the expectations of parents of deaf children, diagnosed and treated at the Clinical School of Speech Therapy Course of the University Center of Araraquara (SP), the authors Boscolo and Santos found that in relation to the use of a hearing aid, parents felt sadness, feelings of ambivalence, satisfaction and creating false expectations.

On the question 13 ("Do you recognize that your son/daughter has better quality of life since he/she started using the hearing aids?") it can be said that only 3 parents have doubts about the improvement of the child's quality of life after the use of hearing aids and one parent refer that the child has no greater quality life since hearing aid adaptation. On the other hand, the remaining parents reported that there was an improvement in the child's quality of life. According to the authors, Harrison, Bevilacqua and Formigoni, Tavares, satisfaction with the use of hearing aids is due to the realization of parental expectations. The hearing aid creates the parents a false expectation, hope that the child is again listener and talk as if he hadn't a hearing deficit. Such an event is due to the fact that these parents have an internal healing desire to believe that only the hearing aid could provide speech to the child.

In question 14 ("Which are the characteristics of the hearing aids that you find more relevant to the child's well-being?"), all parents, except 6 of them, considered the adequacy of hearing loss is the most important feature for the child's well-being. The "size" was the response indicated by the rest of the parents. The question 15 ("Do you know other children who uses hearing aids?"), 8 of 20 parents said they didn't know any children who uses hearing aids, while the other parents know it. It was possible to verify that who don't know other children using hearing aids are the parents who gave less positive answers in the questionnaires. The knowledge of children with hearing loss is to very important to the parents. Knowing other people with hearing loss who have already attained a certain way of adjustment in life to the world of the listener, represent a reference model for parents, allowing them to reduce their fears and concerns about the future of their children with deficit hearing. ${ }^{3}$
Lewis, Race, Bevilacqua, Luterman and Ross, Harrison, NogueiraMartins \& Borges, Formigoni and Avelar also reported the importance of social contact with other parents. The need to share knowledge and the suffering, to offer and exchange information and experiences, provides learning between parents to certain situations of daily life. Contact with parents is one way to minimize actual suffering after the confirmation of the diagnosis of disability.

\section{Conclusion}

Taking in account the answers was possible to verify that the parents with high level of education had more negative responses. Relative to the profession was found that the parents with a less qualified profession had more positive answers. Also can behold that the parents with more negative responses matches to the cases where the interval between diagnosis and the rehabilitation was longer. Was possible to see as well that some parent's evidence bothered when the child wears the hearing aids either by the size or the people's comments. Despite the existence of several studies on child hearing impairment, it was found that the description of the impact of hearing loss in parental behavior is scarce. Thus, this study was justified by the increase of knowledge in the face of prospects expected by parents on how they behave and adapt.

\section{Acknowledgments}

None.

\section{Conflicts of interest}

Author declares there are no conflicts of interest.

\section{Funding}

None.

\section{References}

1. Mendonça CL. Early Diagnosis for Hearing Loss. Recife: Center of Expertise in Speech Therapy Clinic (CEFAC). 1999.

2. Rodrigues AF, Pires A.Children's Hearing Loss and Parental Behavior. Psychological analysis. 2002;20(3):389-400.

3. Almeida K, Lorio MCM. Hearing Aids: Theoretical and Clinical Applications. (2nd edn), São Paulo, Brazil. 2003.

4. Macedo JCGM. Elisabeth Kubler-Ross: The need for education to death. [Dissertation] Minho University: Institute of Education and Psychology. 2004.

5. Pereira MC, Silva AB, Zanolli ML. Hearing Loss: Report of Mothers facing the diagnosis. Psychology Studies. 2008;3(2):175-183. 